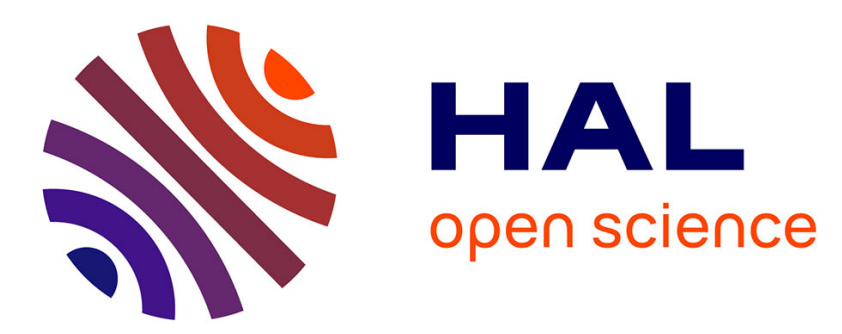

\title{
Impurity identification and characterization by electrical optical and nuclear methods. The ZnTe: Au case
}

N. Magnea, J.L. Pautrat, K. Saminadayar, B. Pajot, P. Martin, A. Bontemps

\section{To cite this version:}

N. Magnea, J.L. Pautrat, K. Saminadayar, B. Pajot, P. Martin, et al.. Impurity identification and characterization by electrical optical and nuclear methods. The ZnTe: Au case. Revue de Physique Appliquée, 1980, 15 (3), pp.701-706. 10.1051/rphysap:01980001503070100 . jpa-00244778

\section{HAL Id: jpa-00244778 https://hal.science/jpa-00244778}

Submitted on 1 Jan 1980

HAL is a multi-disciplinary open access archive for the deposit and dissemination of scientific research documents, whether they are published or not. The documents may come from teaching and research institutions in France or abroad, or from public or private research centers.
L'archive ouverte pluridisciplinaire HAL, est destinée au dépôt et à la diffusion de documents scientifiques de niveau recherche, publiés ou non, émanant des établissements d'enseignement et de recherche français ou étrangers, des laboratoires publics ou privés. 
Classification

Physics Abstracts

$61.70 \mathrm{~W}-61.80 \mathrm{M}-71.35-71.55-72.80 \mathrm{E}$

\title{
Impurity identification and characterization by electrical optical and nuclear methods. The ZnTe : Au case (*)
}

\author{
N. Magnea, J. L. Pautrat, K. Saminadayar, B. Pajot (**), P. Martin and A. Bontemps \\ Centre d'Etudes Nucléaires de Grenoble, Département de Recherche Fondamentale, \\ Section de Physique du Solide, 85 X, 38041 Grenoble Cedex, France
}

\begin{abstract}
Résumé. - L'or introduit par diffusion dans du tellurure de zinc de haute pureté a été caractérisé par des mesures de capacité, de luminescence et d'absorption infrarouge. La position de l'or dans le réseau est analysée par canalisation de particules chargées. Il apparaît que l'or se trouve principalement en site substitutionnel $\left(\mathrm{Au}_{\mathrm{Zn}_{\mathrm{n}}}\right)$ et donne un accepteur simple à $272 \mathrm{meV}$ de la bande de valence.
\end{abstract}

\begin{abstract}
Gold is characterized in pure $\mathrm{ZnTe}$ by capacitance, luminescence and infrared absorption experiments. The position of gold in the lattice is analysed by channeling of charged particules. We show that gold is principally introduced in substitutional position $\left(\mathrm{Au}_{\mathrm{z}_{\mathrm{n}}}\right)$ and give a simple acceptor level at $E_{\mathrm{v}}+272 \mathrm{meV}$.
\end{abstract}

1. Introduction. - The progress in the understanding of a semiconductor material's properties requires the identification of the main impurities. This problem is particularly crucial for the compound semiconductors whose type inversion has not been succeeded today. The identification itself needs first to establish a link between the physical properties observed and the chemical nature of the impurity. This last point needs the use of a chemically selective method for doping the crystal (diffusion, ion implantation, etc...) or for analysing it (ion profiling, mass spectrometry, isotopic effects, etc...). After that, the complete characterization of the impurity needs to establish the catalogue of its electrical and optical parameters like symmetry and localisation of the occupied site, ionisation energy $E_{\mathrm{a}}$, levels of the $\mathrm{s}$ and p excited states, capture cross section, optical ionization cross section.

Such a complete set of data has been established for a given impurity : gold in $\mathrm{ZnTe}$. In fact the luminescence spectra of pure undoped $\mathrm{ZnTe}$ crystals contain a lot of bound exciton lines related to various acceptor impurities [1]. Some of these acceptors are precisely labelled with their associated two hole transitions observable even in as grown crystals. But some of the bound excitons lines are not associated with any two hole replicas. This is the case of a line at $2.3628 \mathrm{eV}$ (5 247,1 $\AA$ ) which is irregularly present in all crystals but, remains generally weak excepted when a gold

$\left(^{*}\right)$ Conférence présentée au Congrès de la Société Française de Physique (Toulouse).

(**) Groupe de Physique ENS. Université Paris VII. diffusion has been done [2]. This was the starting point of the identification procedure described below.

2. Experimental procedure. - $\mathrm{ZnTe}$ crystals are grown at $1100^{\circ} \mathrm{C}$ by a Bridgman method using a Tellurium excess as solvent. The crystals are sliced and mirror polished before chemical etching in a solution of bromine in methanol. As grown crystals contain $\sim 1 \times 10^{15} \mathrm{~cm}^{-3} \mathrm{Cu}_{\mathrm{zn}}$ impurities but $\mathrm{Te}$ inclusions and precipitates always present in the crystal contain a larger amount of lithium and copper $[3,4]$ able to raise the acceptor concentration

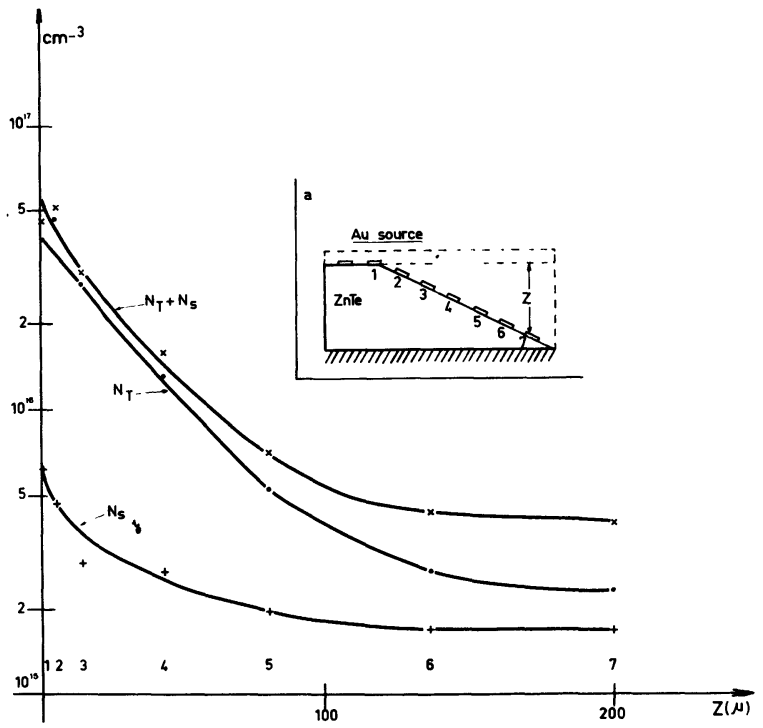

Fig. 1. - Electrical profile of a gold diffused ZnTe sample obtained as shown in the inset (a). Curve $N_{\mathrm{S}}+N_{\mathrm{t}}$ gives the all acceptor concentration, curbe $N_{\mathrm{t}}$ is the deep acceptor profile whereas $N_{\mathrm{S}}$ is the profile of the shallow acceptors. 
in the $10^{16} \mathrm{~cm}^{-3}$ range after proper annealing. Some of the crystals used for this work contain a small amount $\left(4 \times 10^{15} \mathrm{~cm}^{-3}\right)$ of phosphorus impurities due to intentional doping of the melt. For diffusion purposes the $\mathrm{ZnTe}$ slice is gold plated and annealed in the $400-600{ }^{\circ} \mathrm{C}$ range for 1 hour in a $\mathrm{N}_{2}-\mathrm{H}_{2}$ mixture $\left(10 \% \mathrm{H}_{2}\right)$. After that gold is mechanically polished out and the crystal is wedge shaped for in depth analysis of the crystal (see Fig. 1a). After a final chemical etching, the crystal is ready for analysis by electrical, nuclear and optical methods. Experimental details will be given together with the description of the corresponding results.

3. Electrical profile of in-diffused acceptors. The wedge shaped crystal is covered with regularly spaced indium electrodes of diameter $0.4 \mathrm{~mm}$. Due to the wedge angle $(5 \%)$ each metallic electrode probes a $20 \mu \mathrm{m}$ thick region more or less far away from the original diffusion source. The capacitance of the Schottky diodes is measured vs. voltage and analysed in a conventional way in order to extract the total concentration of acceptors since

$$
\mathrm{d} C^{-2} / \mathrm{d} V \simeq 1 /\left(N_{\mathrm{t}}+N_{\mathrm{s}}\right)
$$

if $N_{\mathrm{t}}$ and $N_{\mathrm{s}}$ refer respectively to a deep and shallow acceptor. The deduced concentration is correct even if the deep acceptor is not fully ionized in the bulk material. The analysed zone covers the space charge region width which is about of $1 \mu$ in the $10^{15} \mathrm{~cm}^{-3}$ range so that the resolution is fixed by the geometrical parameters.

The all acceptor profile is shown in figure 1 (curve $N_{\mathrm{t}}+N_{\mathrm{s}}$ ). It demonstrates the in diffusion of an acceptor species. The initial doping $\left(2 \times 10^{15} \mathrm{~cm}^{-3}\right)$ of the slice is shown. At this stage we need a specific analysis in order to separate $N_{\mathrm{t}}$ and $N_{\mathrm{s}}$ and to get the ionization energy of this acceptor.

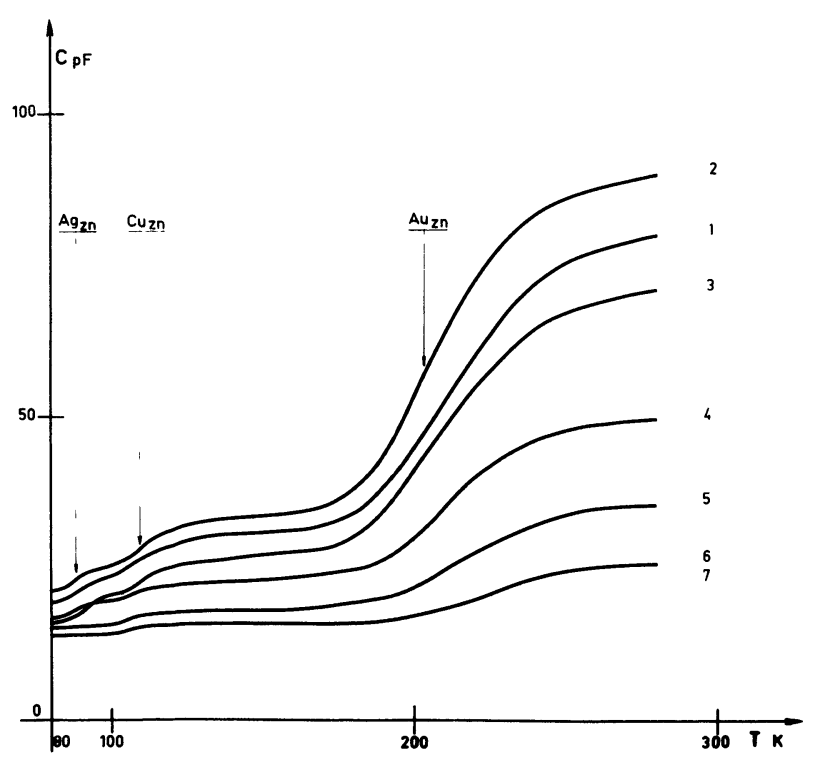

Fig. 2. - Variation with temperature of the capacitance of Schottky diodes with various amount of gold doping.
The existence of a deep acceptor is evidenced by the capacitance variation obtained on cooling down the sample (Fig. 2) : the capacitance step at $\sim 200 \mathrm{~K}$ indicates a deep acceptor. The starting material was $P$-doped and the free hole do not freeze out before $45 \mathrm{~K}$. The small step at $100 \mathrm{~K}$ has been shown to be related to residual $\mathrm{Cu}_{\mathrm{Zn}_{\mathrm{n}}}[2,4,6]$. The smaller step at $90 \mathrm{~K}$ distinguishable only on the upper diodes is due to a small $\mathrm{Ag}_{\mathrm{z}_{\mathrm{n}}}$ diffusion simultaneous with the gold diffusion (contamination of the source ?).

The main step can be used to deduce the $N_{\mathrm{t}}$ concentration when the depth of the level is known $[5,6]$. Using the value obtained below we have calculated the deep acceptor profile (curve $N_{\mathrm{t}}$ of figure 1) and deduced the shallow acceptor concentration (curve $\left.N_{\mathrm{s}}\right)$.

The $N_{\mathrm{s}}$ values determined in that way far from the diffusion surface are very similar to initial doping of the crystal. Near the surface there is some increase in the shallow acceptor concentration which may be attributed to the silver impurity which has diffused simultaneously.

4. Ionization energy of the deep acceptor. - The capacitance step of figure 2 is accompanied by a conductance peak centred on the middle of the step. It can be shown [6] that the peak occur at the temperature where the condition

$$
\omega \tau=1
$$

is satisfied with

$\tau=\sigma v_{\mathrm{t}} N_{\mathrm{v}} \mathrm{e}^{-E_{\mathrm{a}} / k T}\left(1-\frac{N_{\mathrm{t}}}{N_{\mathrm{t}}+N_{\mathrm{s}}}\right)\left(1-\frac{\Delta C}{C}\right)^{-1}$

$\sigma$ is the capture cross section, $v_{\mathrm{t}}$ is the thermal velocity of the holes, $N_{\mathrm{v}}$ the valence band density of states, $E_{\mathrm{a}}$ is the ionization energy of the level, $\Delta C$ is the height

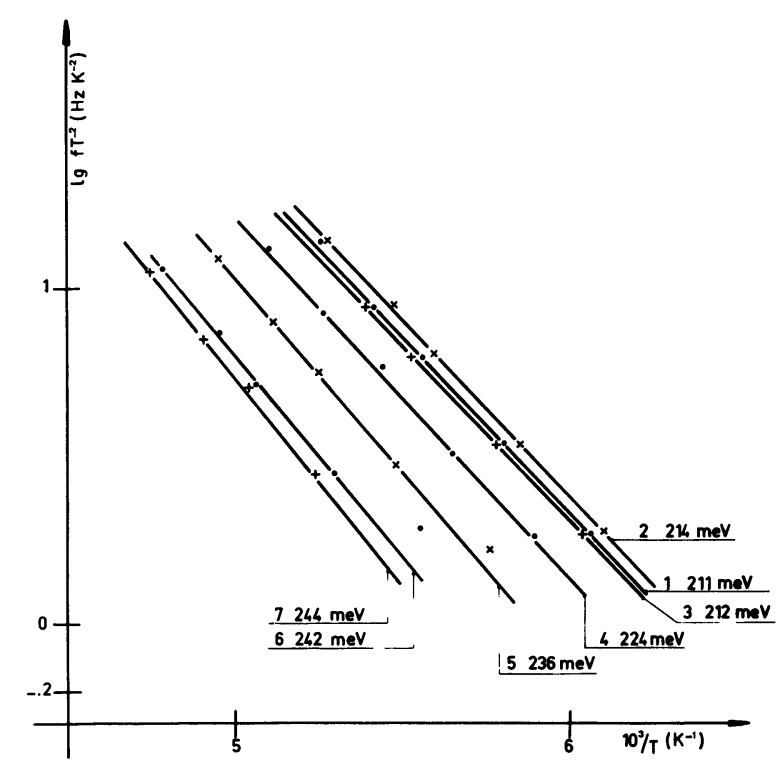

Fig. 3. - Plot of $f T^{-2}$ versus reciprocal temperature at the conductance peak. 
Table I. - Electrical parameters of several Schot tky diodes obtained on a gold diffused sample. $\Delta C / C$ is the relative height of the gold associated capacitance step. $N_{\mathrm{t}}$ and $N_{\mathrm{s}}$ are respectively the concentrations of the deep (gold) and shallow (copper, silver and phosphorous) acceptors. $E_{\mathrm{a}}$ is the experimental activation energy. $\Delta E$ is the theoretical lowering and $E_{\text {corr }}$ is the corrected value $\left(E_{\mathrm{a}}+\Delta E\right)$. $E_{\mathrm{A}}^{\mathrm{Au}}$ is the optically measured ionization energy of $\mathrm{Au}_{\mathrm{Zn}}$. $\sigma$ is the corrected capture cross section.

\begin{tabular}{|c|c|c|c|c|c|c|c|c|}
\hline $\mathrm{Nr}$. & $\Delta C / C$ & $\begin{array}{c}N_{\mathrm{t}} \\
\times 10^{15} \mathrm{~cm}^{-3}\end{array}$ & $\begin{array}{c}N_{\mathrm{s}} \\
\times 10^{15} \mathrm{~cm}^{-3}\end{array}$ & $\begin{array}{c}E_{\mathrm{a}} \\
\mathrm{meV}\end{array}$ & $\begin{array}{c}\Delta E \\
\mathrm{meV}\end{array}$ & $\begin{array}{l}E_{\text {corr }} \\
\mathrm{meV}\end{array}$ & $\begin{array}{c}E_{\mathrm{A}}^{\mathrm{Au}} \\
\mathrm{meV}\end{array}$ & $10^{-15^{\sigma}} \mathrm{cm}^{-2}$ \\
\hline - & - & - & - & - & - & - & - & - \\
\hline 1 & 0.468 & 39.8 & 6.2 & 211 & 38.6 & 249.6 & $272.0 \pm 1$ & 3.38 \\
\hline 2 & 0.523 & 46.9 & 4.7 & 214 & 33.9 & 247.9 & $272.0 \pm 1$ & 2.46 \\
\hline 3 & 0.5 & 26.2 & 3.7 & 212 & 32 & 244 & $272.0 \pm 1$ & 1.9 \\
\hline 4 & 0.42 & 13.3 & 2.7 & 224 & 31.9 & 255.9 & $272.0 \pm 1$ & 4.23 \\
\hline 5 & 0.33 & 4.9 & 2.1 & 236 & 39.6 & 276.6 & $272.0 \pm 1$ & 12.1 \\
\hline 6 & 0.262 & 2.6 & 1.8 & 242 & 29.2 & 259.2 & $272.0 \pm 1$ & 11.5 \\
\hline 7 & 0.238 & 2.3 & 1.7 & 244 & 29.7 & 273.7 & $272.0 \pm 1$ & 10.3 \\
\hline
\end{tabular}

of the step, $C$ is the high temperature value. If the conductance peaks are obtained at several frequencies the plot of $\operatorname{Ln} \omega T^{-2} v s . T^{-1}$ yields a straight line whose slope gives $E_{\mathrm{a}}$ and extrapolation at $T=\infty$ gives $\sigma$. (The $T^{-2}$ term accounts for the temperature dependence of $N_{\mathrm{v}}$ and $v_{\mathrm{t}}$, neglecting the temperature variation of the cross section.) This is the standard method for getting the signature of a given centre [8].

Such a plot shown on figure 3 does not display a constant activation energy but rather a decreasing activation energy for increasing concentrations. Previous work by Aven and Segall yield a value $\sim 220 \mathrm{meV}$ in the range of the present results $(210-244 \mathrm{meV})$. Careful examination of the $C(T)$ and $G(T)$ curves does not show any evidence for a complex situation like that arising for exemple of close centres. In fact, it has been shown after examination of numerous samples that the ionization energy was effectively concentration dependent via the space charge electric field (Poole Frenkel effect) and the coulombic interaction between close impurities which lower the coulombic barrier [9].

These effects can be calculated and the corresponding correction is reported in table I. The corrected activation energies are in the range $282 \pm 15 \mathrm{meV}$ at least for concentration of deep acceptor not too high $N_{\mathrm{t}} / N_{\mathrm{s}}<4$.

For the highest concentrations the simple theory used for calculating the space charge electric field is not sufficient and the corrections cannot be obtained exactly.

Capture cross sections deduced from the curves of figure 3 and reported on table $I$ are about of $10^{-15} \mathrm{~cm}^{2}$ for the less concentrated samples. A direct measurement of the capture cross section would be necessary if a more precise value and its temperature dependence were needed.

These results support the conclusion that the signature of a deep level is very dependent on its environmental conditions and excepted if the doping level and electric field are kept very low, the signature is never an intrinsic one.
5. Nuclear experiments. - The electrical measurements have shown that gold introduces an acceptor in $\mathrm{ZnTe}$. A direct information on the position of the impurity in the lattice can be obtained from channeling experiments which allow to precise, the occupied site (substitutional or interstitial) and eventually in binary compounds the involved sublattice [10].

As gold has an atomic mass higher than that of the elements of the lattice it can be well identified by backscattering of charged particles. When coupled with ionic abrasion this method also provides the concentration profile of the impurity. However the sensitivity remains low (100 ppm) and one can only work on a few tenth of microns below the surface. The crystal is bombarded with $2.2 \mathrm{MeV} \mathrm{B}^{11}$ ions and one detects the number of the particles backscattered by the substrate atoms and the impurity,by varying the angle $\theta$ between the incident beam direction and the principal cristallographic directions of the crystal. For $\theta=0$, the particles can be channeled and the backscattering yield decreases. If the attenuation rate is the same for the substrate and the impurity then one can conclude that the impurity occupies a substitutional site. On the other hand if it is interstitial, it obstructs the channel, then the number of backscattered particles increases. The channeling curve obtained after à $550^{\circ} \mathrm{C} / 1 \mathrm{~h}$ gold diffusion for the three principal axis is shown in figure 4. It appears that :

(i) Gold is on substitutional site because we observe the same attenuation on the lattice and the impurity;

(ii) The fraction of substitutional gold is approximatively $85 \%$ showing its high solubility;

(iii) The sublattice occupied cannot be determined precisely due to the low statistics of counting rate. But electrical and optical measurements demonstrate clearly that gold is acceptor so it shall be on the zinc sublattice.

6. Optical measurements. - The question at that time is to determine exactly the binding energy of the gold acceptor and the visible or infrared transitions 


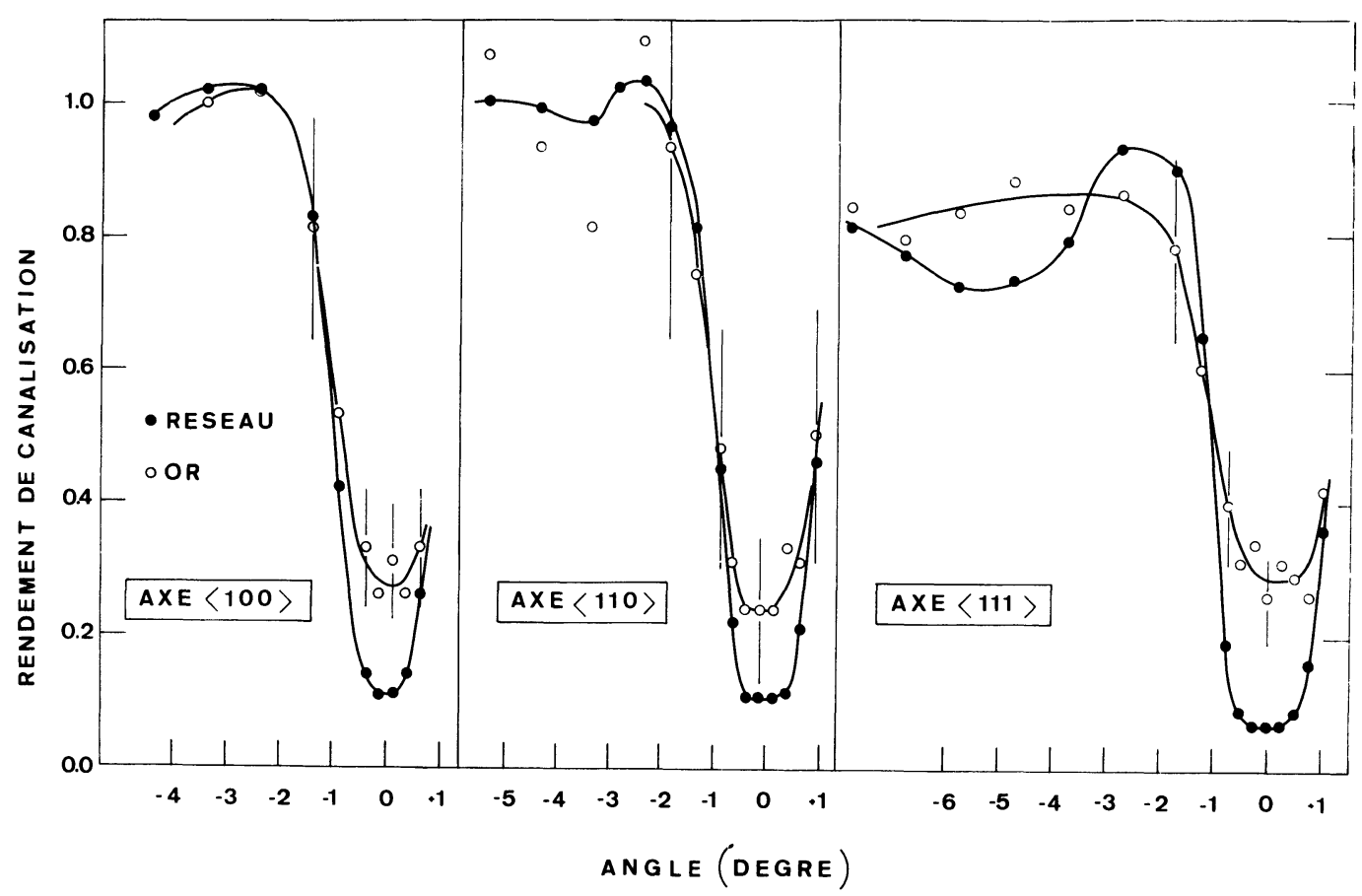

Fig. 4. - Backscattering angular yield scans for both host (Te and $\mathrm{Zn}$ ) and $\mathrm{Au}$ about three principal axis (analysing beam was $2 \mathrm{MeV}$ $\mathrm{B}^{14}$ ions).

which allow an unambiguous identification of this level.

Figure 5 shows the $5 \mathrm{~K}$ photoluminescence (PL) spectrum of gold doped $\mathrm{ZnTe}$ excited with the $4880 \AA$ line of an $\mathrm{Ar}^{+}$ion laser and recorded photoelectrically. The principal bound exciton (PBE) line $\mathrm{A}_{1}^{\mathrm{a}}$ and donoracceptor (DAP) transitions of the $\mathrm{Cu}_{\mathrm{Zn}}(a)$ acceptor present in as grown sample are still observed [1] but a new PBE line $\mathrm{A}_{1}^{\mathrm{Au}}$ at $2.3628 \mathrm{eV}(5247,1 \AA)$ dominates the near gap luminescence. This transition results from the recombination of the bound exciton where the acceptor is left in its ground state. It is also observed in absorption (Fig. 6a) with a splitting resulting from the J-J exchange coupling of the holes in the neutral acceptor-exciton complex (in luminescence the bound exciton excited state $A_{11}^{A u}$ is difficult to observe due to thermalisation). A structure more detailed appearing near $2.12 \mathrm{eV}(5850 \AA)$ is shown in figure $6 b$.

Superimposed on the broad DAP band $\left(\mathrm{D}^{0}, \mathrm{~A}_{\mathrm{Au}}^{0}\right)$ with well resolved $\mathrm{LO}(\Gamma)$ phonon replica sharp lines

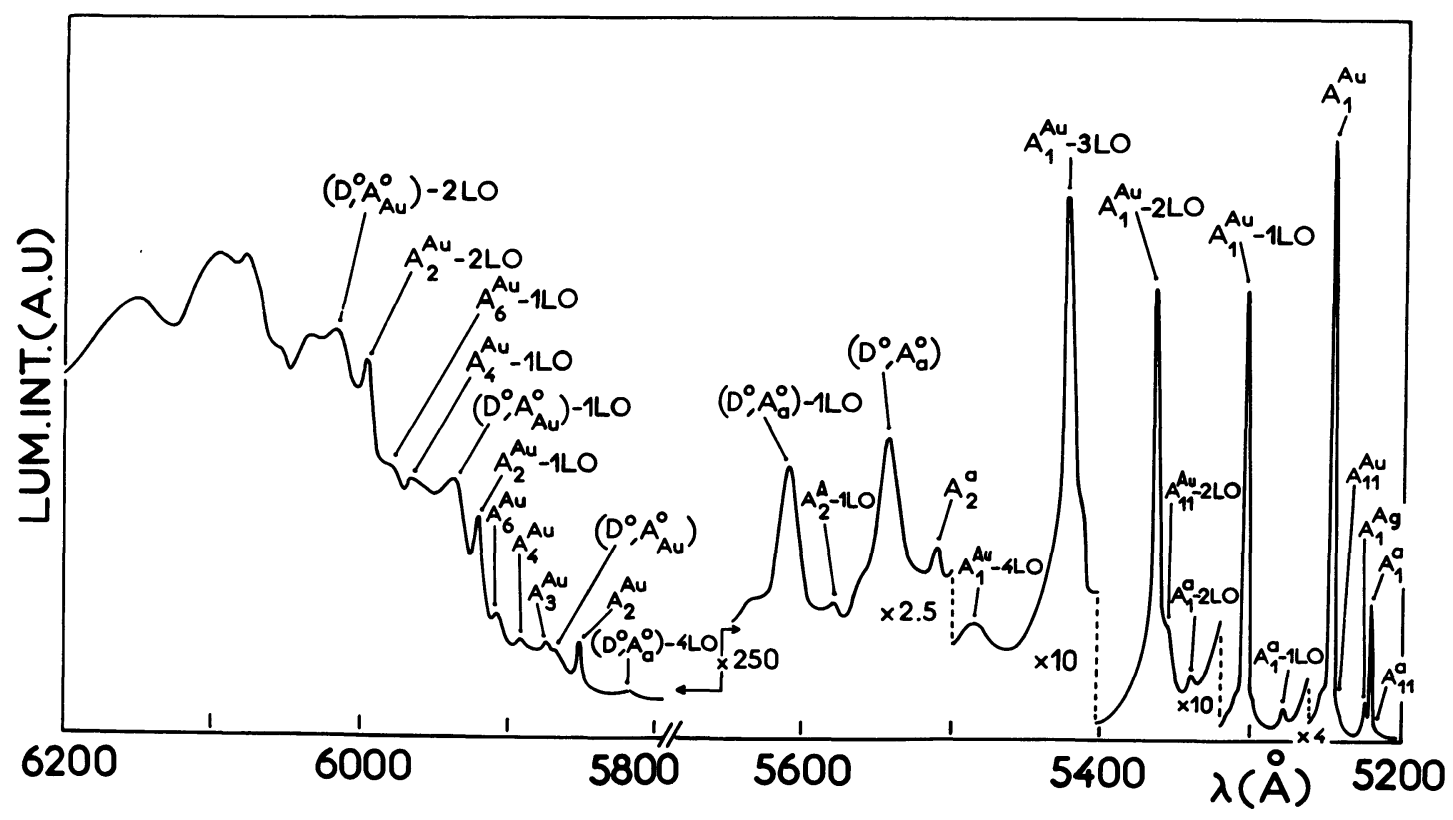

Fig. 5. -- Low temperature photoluminescence spectrum of $\mathrm{ZnTe}: \mathrm{Au}$ with the principal bound exciton line $\left(\mathrm{Au}_{1}^{\mathrm{Au}}\right)$ the two-hole transitions $\left(A_{n}^{A u}\right)$ and the donor-acceptor pairs transitions $\left(D^{0}, A_{A u}^{0}\right)$. 

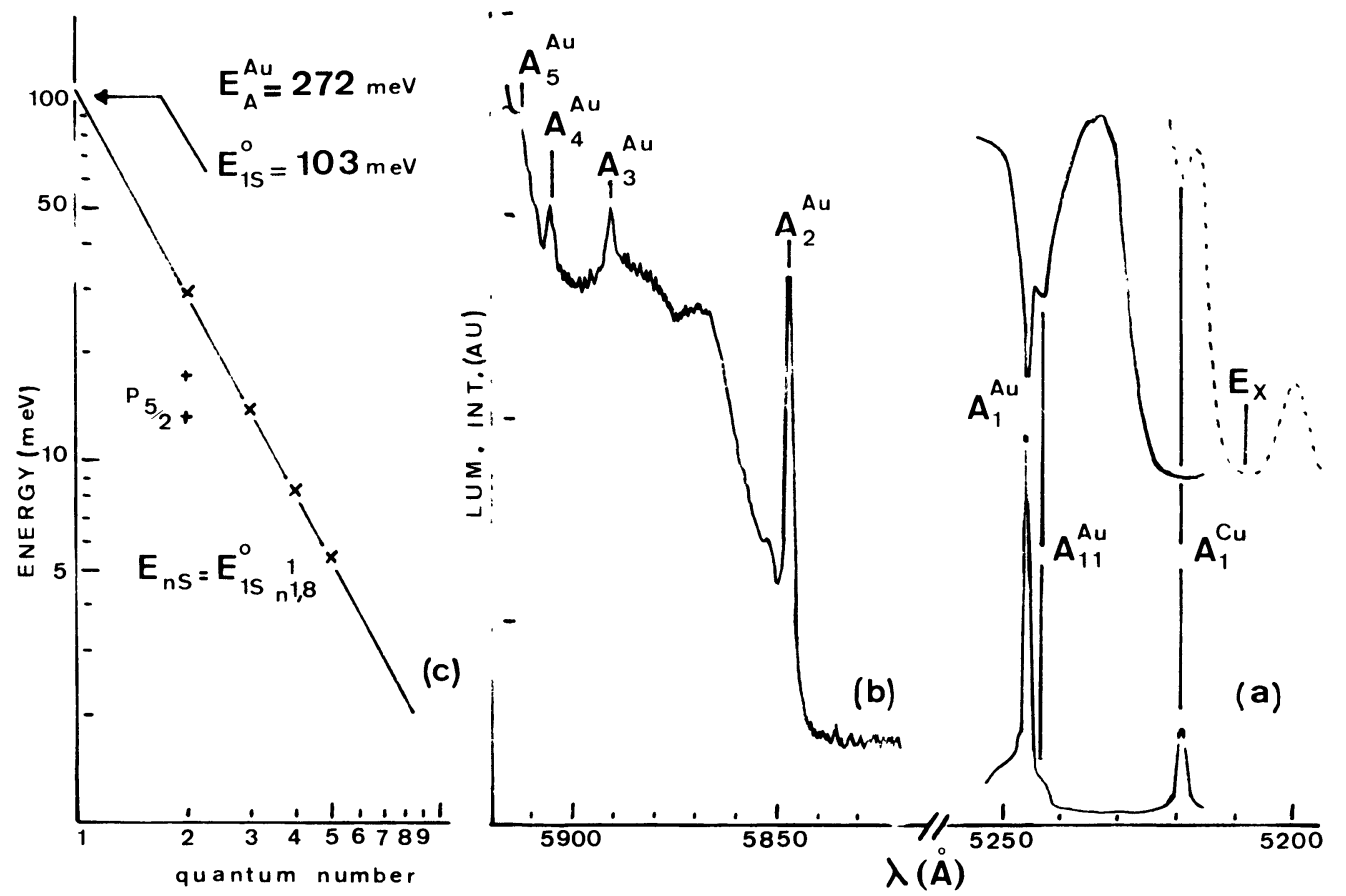

Fig. 6. - (a) Details of the emission and absorption spectra of $\mathrm{A}_{1}^{\mathrm{Au}}$ line. (b) Two-hole transitions $\left(\mathrm{A}_{\mathrm{n}}^{\mathrm{Au}}\right)$ revealing the $\mathrm{nS}_{3 / 2}$ excited states of $\mathrm{Au}_{\mathrm{Zn}^{n}}$. (c) Analyses of the energies of two-hole excited states. Good agreement with the power law indicated in the figure is obtained giving $E_{\mathrm{A}}^{\mathrm{Au}}=272 \mathrm{meV}$.

labelled $\mathrm{A}_{\mathrm{Au}}^{2,3,4}$ can be observed. These lines involves two hole transitions which correspond to the bound exciton recombination with the gold acceptor left in even excited states $\mathrm{nS}_{3 / 2}$ using Baldereschi and Lipari notation [11] due to parity conservation). These transitions thus provides the internal excitation of the acceptor as in $I R$ absorption but with a detection in the visible light range. The spectral shift

$$
\mathrm{A}_{1}^{\mathrm{Au}} \rightarrow \mathrm{A}_{2}^{\mathrm{Au}}(1 \mathrm{~S} \rightarrow 2 \mathrm{~S})
$$

equal to $243.1 \mathrm{meV}$ is characteristic of the involved impurity and can be used as an optical signature for acceptors identifications [2]. This kind of signature is completely intrinsic, independent of doping and electric fields.

Typical $I R$ absorption spectra are presented in figure 7. Two lines at $255.3 \mathrm{meV}$ and $259.0 \mathrm{meV}$ with $\mathrm{LO}(\Gamma)$ phonon replicas are observed. They correspond to the parity allowed transitions between the ground state and the $2 \mathrm{P}_{5 / 2}$ level splitted by the cubic

$Z_{n} T_{e}: A_{u}$

I.R $8 \mathrm{~K}$

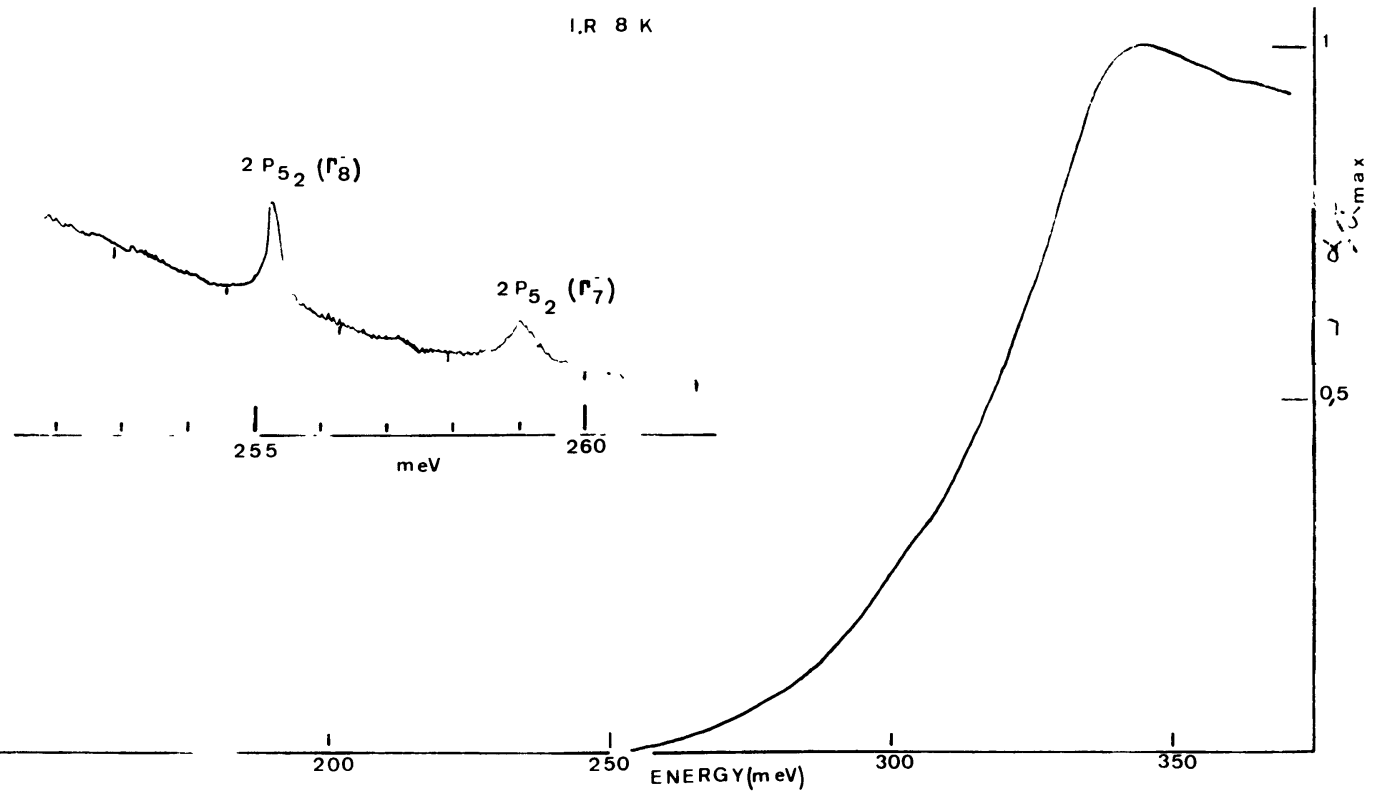

Fig. 7. - Infrared spectra of $\mathrm{ZnTe}$ : Au showing the transition to $\mathrm{P}$ states (insert) and to valence band states. 
term of the valence band in two states with symmetry $\left(\Gamma_{7}\right)$ and $\left(\Gamma_{8}\right)$ [11]. At higher energy we can observe the transitions between the fundamental and the valence band continuum providing the experimental spectral dependence of the photoionization cross section of gold acceptor.

The binding energy $E_{\mathrm{Au}}^{\mathrm{A}}$ of the neutral gold acceptor can be deduced from the $I R$ and $P L$ spectra :

(i) As the $\mathbf{P}$ states evidenced in $I R$ are not affected by the central cell potential, $E_{\mathbf{A}}^{\mathrm{Au}}$ is simply obtained by adding the theoretical ionization energy of the $2 \mathrm{P}_{5 / 2}\left[\left(\Gamma_{7}\right),\left(\Gamma_{8}\right)\right][12]$ levels to the excitation energy obtained in figure 7 . We deduced

$$
E_{\mathrm{A}}^{\mathrm{Au}} \simeq 271.6 \pm 0.5 \mathrm{meV}
$$

(ii) The $\mathrm{nS}_{3 / 2}$ states observed in $P L$ are well described by a modified Rydberg formula (Fig. 6c)

$$
E_{\mathrm{nS}}=E_{1 \mathrm{~s}}^{0} \frac{1}{\mathrm{n}^{1,8}} \quad E_{1 \mathrm{~S}}^{0} \simeq 103 \mathrm{meV} .
$$

The effective Rydberg $E_{1 \mathrm{~s}}^{0}$ is equal to $103 \mathrm{meV}$, to be compared to $57 \mathrm{meV}$ [1] for the hydrogen like acceptor. This strong difference comes from the fact that the central cell potential disturbs the $\mathrm{nS}$ wave function and this distortion can be implicitly included by increasing $E_{\mathrm{is}}^{0}$. From the curve $6 c$ we can obtain the limit of the two-hole serie $\mathrm{A}_{\infty}^{\mathrm{Au}}$ corresponding to the ionization of the acceptor. Then the difference between $\mathrm{A}_{1}^{\mathrm{Au}}$ and $\mathrm{A}_{\infty}^{\mathrm{Au}}$ gives $E_{\mathrm{A}}^{\mathrm{Au}} \simeq 272 \pm 1 \mathrm{meV}$ in very good agreement with $I R$ value.

7. Conclusion. - Several experiments have been necessary to characterize the level introduced by gold in ZnTe. Electrical and optical measurements have shown that it is a single acceptor at $E_{\mathrm{v}}+272 \mathrm{meV}$ while nuclear analysis gives clear evidence that gold is in substitutional position. In this case the simplicity of the diffusion and the high atomic weight of the impurity have made easier the convergence of the different technics showing also the limits of each of them.

(i) Nuclear analysis gives a direct proof of the involved impurity but necessitates high concentration of dopants $\left(10^{18} \mathrm{~cm}^{-3}\right)$;

(ii) Electrical and optical measurements are more sensitive $\left(10^{13}-10^{14} \mathrm{~cm}^{-3}\right)$. The first gives accurate values of doping concentration, but the available signature of the level can be strongly perturbed by the condition of measurements (electric field, doping level). In opposition the optical experiments give the binding energy of the centre with high precision but without quantitative results on the concentrations.

However some problems remain on the behaviour of gold in $\mathrm{ZnTe}$. Particularly we observe a long range tail in the diffusion profile of gold showing that a complicated migration mechanism is involved. Furthermore at high concentrations $\left(10^{17}-10^{18} \mathrm{~cm}^{-3}\right)$ we detect new luminescence lines not reported here. Similar lines have been observed in the case of supersaturation of copper or silver [2]. In all cases the centres responsible of the new features have not been identified but it seems that complex centres with interstitial species are involved.

Acknowledgments. - The authors are grateful to L. Revoil for samples preparation and electrical experiments.

\section{References}

[1] Dean, P. J., Venghaus, H., Pfister, J. C., Schaub, B. and MARINE, J., J. Lumin. 16 (1978) 363.

[2] Magnea, N., Bensahel, D., Pautrat, J. L. and Pfister, J. C., Phys. Status Solidi 94 (1979).

[3] Magnea, N., Bensahel, D. and Pfister, J. C., Solid State Commun. 29 (1979) 35.

[4] Magnea, N., Bensahel, D., Pautrat, J. L., Saminadayar, K. and Pfister, J. C., Solid State Commun. 30 (1979) 259.

[5] Losee, D. L., J. Appl. Phys. 46 (1975) 2204.
[6] Katircioglu, B., Thesis Grenoble (1978) unpublished. Pautrat, J. L. and Katircioglu, B., To be published (1980).

[7] Aven, M. and Segall, B., Phys. Rev. 130 (1963) 81.

[8] Mircea, A., 10th Int. Conf. on Defects and Rad. Effects in Semiconductors, Nice 1978.

[9] Pautrat, J. L., To be published. Solid State Electron. (1980).

[10] Bontemps, A., Thesis Grenoble (1977).

[11] Baldereschi, A., Lipari, N., Phys. Rev. B 8 (1973) 2697.

[12] Herbert, D. C., Dean, P. J., Venghaus, H., Pfister, J. C., J. Phys. C 11 (1978) 3641. 